\title{
KELEMBABAN UDARA DENGAN ALAT HUMYDIMETER PADA LAHAN SAWAH DI KELURAHAN TANAH MERAH
}

\section{AIR HUMIDITY WITH HUMYDIMETER ON RICEFIELDS IN TANAH MERAH WARD}

\author{
Furqaan Hamsyani ${ }^{1 *}$, Herijanto Thamrin ${ }^{1}$, Nurul Asiyah² \\ ${ }^{1}$ Politeknik Pertanian Negeri Samarinda, Jl. Samratulangi PO BOX 192 Samarinda \\ ${ }^{2}$ Mahasiswa Tugas Akhir Politeknik Pertanian Negeri Samarinda, JI. Samratulangi PO BOX \\ 192 Samarinda \\ *corresponding furqaan@politanisamarinda.ac.id
}

\begin{abstract}
Humidity is the concentration of water vapor in the air. In agriculture, air humidity is associated with increased productivity and development of cultivated plants, humidity in the environment where it grows can determine the selection of appropriate plant species, the purpose of this study was to determine air humidity in paddy fields between April, May, and June, changes in air humidity at any time describe the water vapor content in the air can be expressed as absolute humidity, relative or vapor pressure deficit, relative humidity compares the actual water vapor content/pressure with its saturation state or the air's capacity to accommodate water vapor. The relationship between air humidity in paddy fields in Tanah Merah Village is relatively low, this is the impact of changes in temperature, quantity and quality of radiation, wind movement, air pressure, vegetation, and availability of water and productivity of irrigated ricefields.
\end{abstract}

Keywords: Air humidity, rice, ricefields

\section{PENDAHULUAN}

Kelembaban adalah konsentrasi uap air di udara. Angka konsentrasi ini dapat diekspresikan dalam kelembaban absolut, kelembaban spesifik atau kelembapan relatif. Alat untuk mengukur kelembapan disebut higrometer. Sebuah humidistat digunakan untuk mengatur tingkat kelembapan udara dalam sebuah bangunan dengan sebuah pembuat lembab (dehumidifier). Dapat dianalogikan dengan sebuah termometer dan termostat untuk suhu udara. Perubahan tekanan sebagian uap air di udara berhubungan dengan perubahan suhu.

Kelembaban udara merupakan ukuran jumlah uap air di udara. Perkembangan bahan elektronik dan serat optik sudah mendukung dikembangkannya berbagai jenis sensor kelembaban udara dan teknik pengukurannya. Pengukuran kelembaban udara sangat penting di berbagai sektor perindustrian seperti industri pengolahan dan penyimpanan makanan, agrikultur, farmasi, biomedis, bahan kimia, ekologi, pemantauan kondisi cuaca atmosfer dan perindustrian lainnya.

Kelembaban udara merupakan faktor yang penting untuk pertumbuhan tanaman. Tingkat kelembaban udara untuk tiap tanaman mempunyai tingkat yang berbeda- beda. Agar tingkat kelembaban udara untuk tanaman dapat stabil diperlukan alat pengontrol kelembaban udara yang dapat menstabilkan keadaan kelembaban di suatu ruangan. Dengan keadaan kelembaban udara yang baik dan stabil pertumbuhan tanaman akan lebih cepat dan baik, dengan teknologi penanganan dan pengolahan hasil pertanian. Teknologi penanganan tersebut adalah teknologi 
Hamsyani, F., Thamrin, H. dan Asiya, N .(2021) "Kelembaban Udara Dengan Alat Humydimeter Pada Lahan Sawah Di Kelurahan Tanah Merah", Jurnal Agriment, 6(2).

agar tingkat kelembaban udara suatu tanaman yang sedang tumbuh dapat terjaga dengan baik.

Adapun rumusan masalahnya apakah ada perbedaan kelembaban udara di lahan sawah antara bulan April, Mei, dan Juni dengan alat Humidymeter. Sedangkan tujuan penelitian adalah mengetahui kelembaban udara di lahan sawah antara bulan April, Mei, dan Juni dengan alat Humidymeter. Hasil yang diharapakan dapat memberikan informasi kelembaban udara dan cara penggunaan alat Humidymeter.

\section{METODOLOGI}

Lokasi penelitian: penelitian dilaksanakan di Kelurahan Tanah Merah, Kecamatan Samarinda Utara, Kotamadya Samarinda, Propinsi Kalimantan Timur.

Waktu penelitian dilaksanakan selama 3 bulan dimana dari bulan April, bulan Mei dan bulan Juni tahun 2019 dimana dibagi dalam 3 bagian yaitu yang pertama adalah selesai masa panen dan yang kedua masa penanaman padi serta masa pertumbuhan padi dan dibagi menjadi per 15 hari.

Alat dan bahan yang digunakan dalam penelitian: Alat pengukuran kelembaban udara yaitu YK_90HT, full safety, kemera, stop watch, kalkulator, alat tulis, kertas tebel pengukuran.

Tahapan prosedur penelitian:

1. Survery lokasi penelitian (bertemu langsung dengan pemilik lahan dan buruh pekerja lahan sawah);

2. Menentukan titik sampel;

3. Menempatkan rambu-rambu tanda bahwa diadakan penelitian;

4. Alat pengukuran kelembaban udara diletakkan di kelima titik bergantian dilaksanakan antara jam $09.00 \mathrm{~s} / \mathrm{d}$ 12.00 wita dengan safety lengkap;

5. Menghitung rata-rata.
Prosedur alat
kelembaban udara YK_90 HT

1. Periksa terlebih dahulu alat pengukur kelembaban udara YK_90 HT di laboratorium, layak atau tidak dan dicatat serta ditanda tangani oleh PLP sebelum dibawa ke lokasi penelitian;

2. Periksa kembali alat pengukur kelembaban udara YK_90 HT di lokasi penelitian layak atau tidak sebelum digunakan;

3. Setelah alat layak maka tekan tombol power lalu menunggu hingga angka yang tertera pada monitor menjadi stabil;

4. Letakkan alat pengukur kelembaban udara YK_90 HT pada sawah di ke empat sudut dan yang kelima berada ditengah-tangah sawah, dan meletakan alat pengukur kelembaban udara YK_90 HT diatas permukaan tanah dengan posisi rebah 450 dengan berpangku sandaran alat yang disediakan di alat pengukur kelembaban udara YK_90 HT;

5. Tekan tombol "Record/Rec" untuk merekam data tunggu selama 2 menit untuk melihat hasil maksimal dan minimal yang terlihat pada layar, dan di uang selama 5 kali dan mencatat hasil tersebut di kertas tabel pengukuran;

6. Periksa terlebih dahulu kondisi alat setelah penelitian apakah masih dalam kondisi bagus atau tidak, jika kondisi tidak bagus diberi catatan apa saja kerusakan yang terjadi.

7. Periksa kembali kondisi alat dihadapan PLP agar lebih jelas mengenai kondisi alat dengan catatan dari lapangan apa saja kendala dalam pemakaian alat tersebut. 
8. Penanda tanganan berita serah terima alat ke PLP dalam kondisi bagus dan atau dengan catatan.

\section{HASIL DAN PEMBAHASAN}

\begin{abstract}
Berdasarkan Informasi dari Observasi lapangan dan pengukuran kelembaban udara yang dilakukan oleh peneliti di Kelurahan Tanah Merah, Kecamatan Samarinda Utara, Kotamadya Samarinda, Propinsi Kalimantan Timur. Dengan waktu penelitian dilaksanakan selama 3 bulan dimana dari bulan April (selesai masa panen), bulan Mei (masa penanaman padi) dan bulan Juni (masa pertumbuhan padi) tahun 2019 dan dibagi menjadi per 15 hari dalam 1 bulan, dapat dilihat pada tabel 1.
\end{abstract}

Berdasarkan pada tabel 1 diatas terlihat bahwa bulan April kelembaban di tanah per 15 hari ke-1 tinggi pada titik 1 kemudian menurun pada titik 2 dan terendah pada titik 3 kemudian meningkat lagi pada titik 4 , paling tinggi pada titik 5 terjadi pada hal yang sama pada maksimal dan minimal, hal ini terjadi yang sama pada per 15 hari ke-2. Pada bulan Mei per 15 hari ke-1 pada maksimal dan minimal dimana titik 1 cukup tinggi kemudian tertinggi titik ke-2 kemudian menurun lagi titik 3 dan terus menurun titik ke-4 kemudian terjadi peningkatan pada titik ke-5, hal ini juga berlaku pada per 15 hari ke-2.

Bulan Juni per 15 hari ke-1 baik maksimal dan minimal mengalami pergerakan dimana titik ke-1 cukup tinggi kemudian turun pada titik ke-2 dan secara tajam pada titik ke-3 kemudian meningkat tertinggi titik ke-4 dan turun satu tingkat pada titik ke-5, ternyata berlaku juga pada per 15 hari ke-2. Hal ini terlihat bahwa perubahan kelembaban udara setiap saat menggambarkan kandungan uap air di udara dapat dinyatakan sebagai kelembaban mutlak, nisbi maupun defisit tekanan uap, kelembaban nisbi membandingkan antara kandungan/tekanan uap air aktual dengan keadaan jenuhnya atau pada kapasitas udara untuk menampung uap air. Kelembaban udara menggambarkan kandungan uap air di udara yang dapat dinyatakan sebagai kelembaban mutlak, kelembaban nisbi (relatif) maupun defisit tekanan uap air. Kelembaban mutlak adalah kandungan uap air (dapat dinyatakan dengan massa uap air atau tekanannya) per satuan volum. Kelembaban nisbi membandingkan antara kandungan/tekanan uap air aktual dengan keadaan jenuhnya atau pada kapasitas udara untuk menampung uap air.Kapasitas udara untuk menampung uap air tersebut (pada keadaan jenuh) ditentukan oleh suhu udara.Sedangkan defisit tekanan uap air adalah selisih antara tekanan uap jenuh dan tekanan uap aktual. Masing-masing pernyataan kelembaban udara tersebut mempunyai arti dan fungsi tertentu dikaitkan dengan masalah yang dibahas (Handoko,1994). Hal ini dinyatakan juga bahwa Semua uap air yang ada di dalam udara berasal dari penguapan. Penguapan adalah perubahan air dari keadaan cair kekeadaan gas. Pada proses penguapan diperlukan atau dipakai panas, sedangkan pada pengembunan dilepaskan panas. Seperti diketahui, penguapan tidak hanya terjadi pada permukaan air yang terbuka saja, tetapi dapat juga terjadi langsung dari tanah dan lebih-lebih dari tumbuhtumbuhan.Penguapan dari tiga tempat itu disebut dengan Evaporasi (Karim,1985).

Kelembaban relatif dari suatu campuran udara-air didefinisikan sebagai rasio dari tekanan parsial uap air dalam campuran terhadap tekanan uap jenuh air pada temperatur tersebut.Perhitungan kelembaban relatif ini merupakan salah satu data yang dibutuhkan (selain suhu, curah hujan, dan observasi visual terhadap vegetasi) (Santoso, 2007). Tinggi rendahnya kelembaban udara di suatu tempat sangat bergantung pada beberapa faktor sebagai berikut: 
Hamsyani, F., Thamrin, H. dan Asiya, N .(2021) "Kelembaban Udara Dengan Alat Humydimeter Pada Lahan Sawah Di Kelurahan Tanah Merah", Jurnal Agriment, 6(2).

Tabel 1. Kelembaban Udara (\%) Pada Pengambilan Sampel Bulan April dan Bulan Mei Per 15 Hari

$$
\text { Bulan April Bulan Mei Bulan Juni }
$$

Titik Per 15 Hari Ke-1 Per 15 Hari Ke-2 Per 15 Hari Ke-1 Per 15 Hari Ke-2 Per 15 Hari Ke-1 Per 15 Hari Ke-2

\begin{tabular}{|c|c|c|c|c|c|c|c|c|c|c|c|c|}
\hline & Maks & Min & Maks & Min & Maks & Min & Maks & Min & Maks & Min & Maks & Min \\
\hline \multirow[t]{5}{*}{1} & 75,49 & 72,85 & 74,25 & 74,06 & 71,51 & 68,25 & 72,75 & 67,04 & 79,17 & 68,72 & 80,38 & 67,48 \\
\hline & 70,90 & 65,00 & 71,91 & 63,97 & 63,86 & 62,42 & 62,85 & 63,45 & 74,24 & 69,56 & 73,21 & 70,57 \\
\hline & 60,78 & 56,45 & 59,66 & 57,55 & 69,83 & 64,44 & 70,95 & 63,34 & 72,59 & 62,32 & 73,69 & 61,20 \\
\hline & 62,00 & 56,40 & 63,21 & 55,21 & 66,23 & 63,91 & 65,02 & 65,10 & 72,57 & 65,58 & 71,38 & 66,79 \\
\hline & 60,07 & 50,55 & 61,37 & 51,82 & 66,11 & 64,32 & 67,41 & 63,05 & 70,85 & 67,07 & 72,12 & 68,37 \\
\hline Jumlah & 329,24 & 301,25 & 330,40 & 302,61 & 337,54 & 323,34 & 338,98 & 321,98 & 369,42 & 333,25 & 370,78 & 334,41 \\
\hline Rata-rata & 65,85 & 60,25 & 66,08 & 60,52 & 67,51 & 64,67 & 67,80 & 64,40 & 73,88 & 66,65 & 74,16 & 66,88 \\
\hline \multirow[t]{5}{*}{2} & 58,39 & 50,82 & 59,63 & 52,03 & 97,25 & 71,12 & 96,01 & 72,33 & 75,27 & 55,26 & 76,48 & 56,50 \\
\hline & 60,67 & 55,43 & 61,68 & 56,46 & 77,42 & 75,79 & 78,43 & 74,76 & 55,12 & 43,13 & 56,15 & 44,14 \\
\hline & 67,47 & 57,92 & 68,59 & 59,02 & 76,49 & 72,38 & 75,37 & 73,48 & 42,89 & 38,75 & 43,99 & 39,87 \\
\hline & 62,07 & 56,44 & 63,28 & 57,63 & 74,94 & 74,04 & 76,15 & 72,85 & 45,89 & 36,13 & 47,08 & 37,34 \\
\hline & 60,07 & 50,53 & 61,37 & 51,80 & 75,16 & 72,90 & 76,46 & 74,17 & 49,62 & 39,89 & 50,89 & 41,19 \\
\hline Jumlah & 308,67 & 271,14 & 314,55 & 276,94 & 401,26 & 366,23 & 402,42 & 367,59 & 268,79 & 213,16 & 274,59 & 219,04 \\
\hline Rata-rata & 61,73 & 54,23 & 62,91 & 55,39 & 80,25 & 73,25 & 80,48 & 73,52 & 53,76 & 42,63 & 54,92 & 43,81 \\
\hline \multirow[t]{5}{*}{3} & 59,12 & 54,20 & 57,88 & 55,41 & 81,12 & 63,19 & 82,36 & 64,40 & 54,70 & 43,90 & 55,91 & 42,66 \\
\hline & 56,60 & 53,98 & 57,61 & 52,95 & 70,65 & 65,25 & 71,66 & 66,28 & 44,78 & 44,78 & 43,75 & 45,79 \\
\hline & 58,35 & 53,42 & 57,23 & 54,52 & 63,95 & 60,85 & 65,07 & 61,95 & 42,74 & 42,74 & 43,84 & 41,62 \\
\hline & 51,86 & 48,50 & 53,07 & 47,31 & 64,72 & 58,78 & 65,93 & 59,97 & 47,78 & 74,78 & 46,59 & 75,99 \\
\hline & 45,79 & 48,21 & 47,09 & 49,48 & 58,87 & 55,46 & 60,17 & 56,73 & 44,31 & 44,31 & 45,58 & 45,61 \\
\hline Jumlah & 271,72 & 258,31 & 272,88 & 259,67 & 339,31 & 303,53 & 345,19 & 309,33 & 234,31 & 250,51 & 235,67 & 251,67 \\
\hline Rata-rata & 54,34 & 51,66 & 54,58 & 51,93 & 67,86 & 60,71 & 69,04 & 61,87 & 46,86 & 50,10 & 47,13 & 50,33 \\
\hline \multirow[t]{5}{*}{4} & 72,60 & 63,04 & 73,84 & 61,83 & 63,28 & 65,43 & 62,04 & 66,64 & 77,06 & 60,25 & 75,85 & 61,49 \\
\hline & 66,33 & 60,47 & 65,32 & 61,50 & 66,60 & 53,22 & 67,61 & 52,19 & 77,10 & 69,66 & 78,13 & 68,65 \\
\hline & 60,28 & 51,47 & 61,40 & 50,37 & 66,68 & 60,67 & 65,56 & 61,77 & 83,19 & 74,13 & 82,09 & 75,25 \\
\hline & 59,72 & 57,22 & 58,51 & 58,41 & 66,08 & 60,66 & 67,29 & 59,47 & 82,05 & 73,65 & 83,24 & 72,44 \\
\hline & 65,33 & 65,06 & 66,63 & 63,79 & 58,74 & 54,80 & 60,04 & 56,07 & 78,34 & 74,21 & 77,07 & 75,51 \\
\hline Jumlah & 324,26 & 297,26 & 325,70 & 295,90 & 321,38 & 294,78 & 322,54 & 296,14 & 397,74 & 351,90 & 396,38 & 353,34 \\
\hline Rata-rata & 64,85 & 59,45 & 65,14 & 59,18 & 64,28 & 58,96 & 64,51 & 59,23 & 79,55 & 70,38 & 79,28 & 70,67 \\
\hline \multirow[t]{5}{*}{5} & 73,50 & 76,25 & 74,74 & 75,04 & 73,50 & 76,25 & 74,74 & 77,46 & 79,38 & 70,47 & 78,17 & 71,71 \\
\hline & 71,51 & 68,50 & 70,50 & 69,53 & 71,51 & 68,50 & 72,52 & 69,53 & 76,79 & 68,58 & 77,82 & 67,57 \\
\hline & 66,86 & 62,74 & 67,98 & 61,64 & 66,86 & 62,74 & 67,98 & 63,84 & 76,83 & 67,16 & 75,73 & 68,28 \\
\hline & 67,30 & 57,31 & 66,09 & 58,50 & 67,30 & 57,31 & 68,51 & 58,50 & 77,79 & 72,72 & 78,98 & 71,51 \\
\hline & 61,53 & 58,85 & 62,83 & 57,58 & 61,51 & 58,85 & 62,81 & 60,12 & 79,19 & 73,15 & 77,92 & 74,45 \\
\hline Jumlah & 340,70 & 323,65 & 342,14 & 322,29 & 340,68 & 323,65 & 346,56 & 329,45 & 389,98 & 352,08 & 388,62 & 353,52 \\
\hline Rata-rata & 68,14 & 64,73 & 68,43 & 64,46 & 68,14 & 64,73 & 69,31 & 65,89 & 78,00 & 70,42 & 77,72 & 70,70 \\
\hline
\end{tabular}

a. Suhu udara adalah ukuran energi kinetik rata - rata dari pergerakan molekul-molekul. Suhu suatu benda ialah keadaan yang menentukan kemampuan benda tersebut, untuk 
memindahkan (transfer) panas ke benda- benda lain atau menerima panas dari benda-benda lain tersebut. Suhu udara adalah derajat panas dari aktifitas molekul dalam atmosfer. Alat untuk mengukur suhu temperature atau derajat panas disebut thermometer. Dimana pada praktikum ini menggunakan thermometer bola kering dan thermometer bola basah. Suhu dan kelembaban udara sangat erat hubungannya, karena jika kelembaban udara berubah, maka suhu juga akan berubah. Di musim penghujan suhu udara rendah, kelembaban tinggi, memungkinkan tumbuhnya jamur pada kertas, atau kertas menjadi bergelombang karena naik turunnya suhu udara;

b. Kuantitas dan kualitas penyinaran Kualitas intensitas, lamanya radiasi yang mengenai tumbuhan mempunyai pengaruh yang besar terhadap berbagai proses fisiologi tumbuhan. Cahaya mempengaruhi pembentukan klorofil, fotosintesis, fototropisme, dan fotoperiodisme;

c. Pergerakan angin memperlihatkan semakin tinggi kecepatan pergerakan angin akan lebih mempercepat pegangkatan uap air menggempul diudara;

d. Tekanan udara dimana tekanan udara erat kaitannya dengan pergerakaan angin;

e. Vegetasi, merupakan hal yang utama diaman semakin banyak vegetasi suatu daerah semakin mempengaruhi tingkat kelembaban suatu daerah, mengingat tanaman termasuk salah satu penghasil uap air melaui proses transpirasi;

f. Ketersediaan air di suatu tempat (air tanah).
Permasalahan sektor pertanian, khususnya padi sawah tadah hujan tidak terlepas dari adanya variabilitas iklim, terutama variabilitas curah hujan. Kajian mengenai dampak variabilitas curah hujan terhadap produktivitas padi sawah tadah hujan penting dilakukan untuk mengetahui sejauh mana hubungan antara keduanya, sehingga pada akhirnya dapat ditentukan pola adaptasi yang sesuai guna mencapai produktivitas padi yang maksimal. Sektor pertanian tidak terlepas dari beberapa faktor, antara lain adalah faktor atmosfer, dimana tanaman pertanian akan produktif pada keadaan atmosfer tertentu saja. Atmosfer bumi adalah suatu sistem yang sifatnya sangat beragam, dengan variabilitas yang terjadi pada kisaran yang sangat besar baik dalam skala waktu maupun jarak (Trewartha, 1995).

Cuaca dan iklim merupakan beberapa proses yang terjadi pada sistem atmosfer bumi. Proses terjadinya cuaca dan iklim merupakan kombinasi dari variabel-variabel atmosfer yang sama yang disebut unsur-unsur iklim. Unsurunsur iklim ini terdiri dari radiasi surya, suhu udara, kelembaban udara, awan, presipitasi, evaporasi, tekanan udara dan angin. Unsur-unsur ini memiliki variasi/perbedaan menurut agihan baik spasial maupun temporal. Perbedaan ini disebabkan pengendali iklim atau yang lebih dikenal dengan faktor penentu iklim. Menurut Lakitan (1994), faktor dominan yang menentukan perbedaan iklim secara spasial antara lain ialah posisi relative terhadap garis edar matahari (posisi lintang), keberadaan lautan atau permukaan airnya, pola arah angin, rupa permukaan daratan bumi (topografi), dan kerapatan dan jenis vegetasi.

Tanaman padi dapat hidup baik didaerah yang berhawa panas dan banyak mengandung uap air. Curah hujan yang baik rata-rata $200 \mathrm{~mm}$ per bulan atau lebih, dengan distribusi selama 4 bulan, curah hujan yang dikehendaki per tahun sekitar 1500- $2000 \mathrm{~mm}$. Suhu yang baik untuk 
Hamsyani, F., Thamrin, H. dan Asiya, N .(2021) "Kelembaban Udara Dengan Alat Humydimeter Pada Lahan Sawah Di Kelurahan Tanah Merah", Jurnal Agriment, 6(2).

pertumbuhan tanaman padi $23^{\circ} \mathrm{C}$. Tinggi tempat yang cocok untuk tanaman padi berkisar antara $0-1500 \mathrm{~m}$ dpl. Faktor yang menentukan keberhasilan perntanian selanjutnya adalah kondisi tanah. Tanah yang baik untuk pertumbuhan tanaman padi adalah tanah sawah yang kandungan fraksi pasir, debu dan lempung dalam perbandingan tertentu dengan diperlukan air dalam jurnlah yang cukup. Padi dapat tumbuh dengan baik pada tanah yang ketebalan lapisan atasnya antara 18 -22 cm dengan $\mathrm{pH}$ antara 4 -7.

Indonesia sebagai Negara agraris memiliki luas lahan sawah yang sangat besar tersebar di hampir seluruh wilayah Indonesia. Sawah adalah lahan usaha tani yang secara fisik, permukaan tanahnya rata, dibatasi oleh pematang, dapat ditanami padi dan palawija/tanaman pangan lainnya. Secara umum, berdasarkan pengairanya, sawah di Indonesia dibagi menjadi dua, yaitu sawah irigasi dan sawah tadah hujan. Sawah irigasi adalah sawah yang sumber air utamanya berasal dari air irigasi, baik berasal dari sungai, waduk, maupun danau, sedangkan sawah tadah hujan adalah sawah yang sumber air utamanya berasal dari curah hujan.

Sistem penanaman padi sawah ialah sistem penanaman dimana tanaman padi ditanam pada tanah sawah yang pada periode tertentu selalu tergenang oleh air. Sistem ini biasa digunakan pada daerah dengan ketersediaan air yang cukup. Sistem budidaya padi gogo rancah ialah sistem penanaman padi yang dibudidayakan dilahan kering. Pada sistem budidaya padi gogo rancah seolaholah kita anggap tanaman padi seperti tanaman palawija, sehingga kebutuhan air dalam sistem ini sangatlah minim. Sistem budidaya padi gogo sering dilakukan pada tanah-tanah yang kering atau tanah tadah hujan.

Proses pada sistem padi walik jerami, benih padi disebar dipesemaian 2 minggu sebelum padi gogo rancah dipanen dan selanjutnya ditanam pindah seperti padi sawah irigasi. Kekuranganya adalah karena padi walik jerami ditanam menjelang musim hujan berakhir, maka seringkali pada stadia berbunga atau pada stadia pengisian dimana tanaman pada saat tersebut membutuhkan air, justru hujan sudah berkurang atau jarang turun karena musim kemarau datang lebih awal. Strategi antisipasi dan adaptasi bidang pertanian terkait perubahan atau anomali iklim, khususnya anomali curah hujan yang terjadi mutlak diperlukan agar produktivitas pertanian tetap terjaga. Mengingat kondisi iklim yang tak lagi menentu, pola adaptasi tidak dapat lagi hanya dilakukan dengan mengandalkan pola musim seperti dahulu. Telah banyak dilakukan penelitian tentang fenomena pergeseran musim, dan hasilnya menyebutkan bahwa seringkali terjadi pergeseran musim, seperti lebih lamanya musim kemarau, atau musim hujan. Hal ini jelas berpengaruh terhadap jadwal tanam petani, khususnya petani padi sawah tadah hujan, yang secara langsung memanfaatkan air hujan sebagai sarana pengairan.

Faktor utama dalam menentukan pola tanam, baik untuk sawah irigasi maupun lahan sawah tadah hujan ialah ketersediaan atau pasokan air. Lahan sawah tadah hujan, pasokan air hanya bergantung dari curah hujan dan letak tropografi suatu daerah. Kebutuhan air untuk tanaman padi, minimal dibutuhkan bulan basah (curah hujan diatas 200 $\mathrm{mm} /$ bulan) secara berurutan minimal 4 bulan. Penentuan frekuensi penanaman padi pada ekosistem sawah tadah hujan sangat ditentukan oleh pola hujan yang ada. Golongan I dengan curah hujan diatas $100 \mathrm{~mm} /$ bulan mencapai 5 bulan dan ada 3 bulan basah berurutan dapat dilakukan 1 kali pertanaman padi gogo rancah, dan untuk pertanaman padi sawah masih bisa dilakukan bila pelumpuran dan 
peresapan air mudah serta ada tambahan air dari bagian atas. Golongan II dengan curah hujan diatas $100 \mathrm{~mm} / \mathrm{bulan}$ mencapai 7 bulan dan ada 5 bulan basah berurutan, dapat dilakukan 1 kali pertanaman padi sawah atau 2 kali padi yang dimulai dengan sistem gogo rancah diikuti padi walik jerami, tapi masih ada resiko kekeringan. Golongan III dengan curah hujan diatas $100 \mathrm{~mm} / \mathrm{bulan}$ mencapai 9 bulan dan ada 7 bulan basah berurutan, dapat dilakukan 2 kali pertanaman padi sawah. Bila curah hujan awal penyebaranya tajam, maka pertanaman pertama sebaiknya dilakukan dengan sistim gogo rancah. Pada golongan IV dengan curah hujan diatas $100 \mathrm{~mm} /$ bulan mencapai 11 bulan dan ada 9 bulan basah yang berurutan, dapat dilakukan 2 kali pertanaman padi sawah (Harwood 1979).

\section{KESIMPULAN}

Hubungan antara kelembaban udara pada lahan sawah di Kelurahan Tanah Merah tergolong rendah, Hal ini dampak dari perubahan suhu, kuantitas dan kualitas penyinaran, pergerakan angina, tekanan udara, vegetasi, dan ketersediaan air serta produktivitas padi sawah irigasi.

\section{DAFTAR PUSTAKA}

Handoko. 1994. Klimatologi Dasar. Pustaka Jaya. Bogor. 192 hal.

Harwood, R.R. 1979. Small farm development understanding and improving farming system in the humid tropies. Boulder Colorado ; Westview Press

Karim K. 1985 Diktat Kuliah Dasar-Dasar Klimatologi. Diterbitkan dengan Biaya Proyek Peningkatan dan Pengembangan Perguruan Tinggi Universitas Syiah Kuala, Banda Aceh

Lakitan, Benyamin. 1994. Dasar-Dasar Klimatologi. Jakarta: Raja Grafindo Persada.
Santoso, B. M, 2007, Sereh Wangi Bertanam dan Penyulingan, Cetakan ke 10, Penerbit Kanisius, Yogyakarta

Trewartha, G. T, dan L. H. Horn. 1995. Pengantar Iklim - Edisi Kelima. Yogyakarta: Gadjah Mada University Press 